\title{
Mechanisms of acetylcholine receptor loss in myasthenia gravis
}

\author{
DANIEL B DRACHMAN, ROBERT N ADAMS, ELIS F STANLEY, AND \\ ALAN PESTRONK
}

From the Department of Neurology, Johns Hopkins University School of Medicine, Baltimore, Maryland, USA

SUMMARY The fundamental abnormality affecting the neuromuscular junctions of myasthenic patients is a reduction of available AChRs, due to an autoimmune attack directed against the receptors. Antibodies to AChR are present in most patients, and there is evidence that they have a predominant pathogenic role in the disease, aided by complement. The mechanism of antibody action involves acceleration of the rate of degradation of AChRs, attributable to cross-linking of the receptors. In addition, antibodies may block $A C h R s$, and may participate in producing destructive changes, perhaps in conjunction with complement. The possibility that cell-mediated mechanisms may play a role in the autoimmune responses of some myasthenic patients remains to be explored. Although the target of the autoimmune attack in myasthenic patients is probably always the acetylcholine receptors, it is not yet clear which of these immune mechanisms are most important. It is likely that the relative role of each mechanism varies from patient to patient. One of the goals of future research will be to identify the relative importance of each of these mechanisms in the individual patient, and to tailor specific immunotherapeutic measures to the abnormalities found.

Reduction of AChRs at neuromuscular junction in $M G$ In 1964, Elmqvist and his colleagues first made the important observation that the amplitude of miniature endplate potentials (mepps) was diminished in muscles from patients with MG. $^{3}$ They concluded that the mepp abnormality was due to a reduction in the amount of $\mathrm{ACh}$ contained in a single quantum. However, there are other theoretically possible explanations of decreased mepp amplitudes, including a reduced number of AChRs or a false transmitter. In order to test the receptor hypothesis, we obtained "motor point" biopsies from ten patients with myasthenia gravis and a group of unaffected individuals and disease controls. The strips of muscle containing endplates were incubated with ${ }^{125} \mathrm{I}-\alpha-\mathrm{BuTx}$, to saturate the AChRs, and the excess $\alpha$-BuTx was removed by washing. The bound ${ }^{125} \mathrm{I}-\alpha$-BuTx was measured by scintillation counting, and autoradiography. Our findings showed a marked reduction of AChRs at neuromuscular junctions of patients with MG, averaging $80 \%$ less than controls. ${ }^{811} 12$ This finding of reduced AChRs at myasthenic neuromuscular junctions

Address for reprint requests: Dr DB Drachman, Department of Neurology, Johns Hopkins School of Medicine, 1721 E. Madison St, Baltimore, Maryland 21205, USA. has subsequently been confirmed by $\alpha$-BuTx binding, ${ }^{13}$ and by electrophysiological methods. ${ }^{14}$ We have continued to carry out motor point biopsies, and our findings suggest that in many cases measurement of junctional AChRs may be the most sensitive test for MG (Pestronk, Drachman, Josifek, in preparation).

\section{Role of AChR deficit in myasthenia}

Our observations raised the question of whether the decrease of available AChRs per se could account for the physiological abnormalities in MG, or whether it represented a secondary phenomenon. In order to explore this question further, we produced pharmacological blockade of AChRs in rats by the use of the $\alpha$-toxin from the cobra Naja naja atra, ${ }^{15}$ and compared the resultant changes in neuromuscular transmission with the abnormalities occurring naturally in myasthenia. ${ }^{16}$ The most effective method of administration of cobra toxin proved to be a single intravenous injection (12 to $20 \mu \mathrm{g}$ ) followed by a long observation period of up to 14 hours. Evoked potentials were recorded from the calf muscles during repetitive stimulation of the sciatic nerve. Initially, the evoked action potentials declined in amplitude as the AChR sites 
were blocked by the toxin. Following equilibration of the toxin in the musculature, the compound action potentials returned to normal or near normal amplitudes. Partial blockade of AChRs developed, with a reduced margin of safety of neuromuscular transmission. During this phase, which remained stable for many hours, the "myasthenic" features were readily seen. Repetitive nerve stimulation at $3 \mathrm{~Hz}$ reproduced the characteristic decremental pattern of MG. Furthermore, these responses were exaggerated by minute doses of d-tubocurarine $(1 / 30$ th of the rat curarising dose), which is typical of the response in human MG. Treatment of the rats with neostigmine $(2 \cdot 5$ to $7 \cdot 5 \mu \mathrm{g}$ intravenously) produced marked improvement or recovery of the decremental responses. Finally, post-tetanic reponses, thought to be particularly characteristic of MG $^{17}$ were also reproduced by the cobra toxin model. Both the early improvement (post-tetanic potentiation) and later exaggeration of the decremental responses (postactivation exhaustion) occurred in the rats. Thus, from the point of view of the electrophysiological features, the cobra toxin model faithfully reproduced the abnormalities found in human MG. Since the $\alpha$-toxin of Naja naja atra used in this study has been shown to block AChRs specifically, ${ }^{15}$ our findings strongly support the hypothesis that a reduction of available receptors per se can account for the defect of neuromuscular transmission in MG.

Autoimmure abnormality in $M G$

The possibility that MG might be an autoimmune disease was originally proposed on the basis of indirect evidence, consisting of a high rate of thymic abnormalities, the association between MG and other presumed autoimmune diseases, ${ }^{7}$ and reduced complement levels in some patients. ${ }^{18}$ A further clue that the autoimmune attack might be directed against AChRs came from the finding that animals immunised with purified AChR in Freund's adjuvant developed a condition analogous to myasthenia. ${ }^{19}$

Based on the knowledge of a receptor deficit in MG, and the analogy with the experimental animal model, the search for antibodies directed against AChRs in the human disease was soon begun. Antireceptor antibody was identified by several different methods, ${ }^{20-24}$ all of which depend on $\alpha$-BuTx for their specificity. In the most sensitive radioimmunoassay, which detects antibody that binds to AChR labelled with ${ }^{125} \mathrm{I}-\alpha$-BuTx, elevated titers have been found in $80-90 \%$ of patients with MG. ${ }^{23}$ However, the antibody titre corresponds only approximately to the clinical status of the patients.
Passive Transfer of $M G$

The question of whether the circulating antibodies are pathogenic, or merely represent a secondary response to $A C h R$ damage caused by some other agent, is of paramount importance in understanding the pathogenesis of MG. A well known "experiment in nature" suggested that a circulating factorpossibly immunoglobulin-might be pathogenic: approximately one of every six infants born to myasthenic mothers manifests transient signs of MG during the first few postnatal weeks. ${ }^{25}$ In the past, the results of numerous attempts ${ }^{26}$ to transfer myasthenia from humans to experimental animals or nerve-muscle preparations were generally negative or were criticised for inherent faults. ${ }^{27}$ However the possibility of a circulating factor assumed new importance in the light of the discovery of antibodies to AChR. In most previous studies, the exposure to myasthenic serum had been brief, lasting minutes to hours. We wondered whether more prolonged exposure to levels of immunoglobulin corresponding to those in the patient, might be required for the effect to take place. We therefore designed an experiment in which physiologic levels of human myasthenic IgG could be maintained in a hardy strain $\left(\mathrm{B}_{6} \mathrm{D}_{2} \mathrm{~F}_{1}\right)$ of experimental mice for up to 14 days. ${ }^{28}$ Immunoglobulin fractions, prepared from the sera of myasthenic patients or controls by ammonium sulfate precipitation, were injected daily into recipient mice. In order to produce tolerance to the foreign serum, we treated the mice with a single dose of cyclophosphamide $(300 \mathrm{mg} / \mathrm{Kg}), 24$ hours after the first dose of immunoglobulin, except in experiments lasting less than four days. Some of the experimental mice became clinically weak within a few days and showed decremental responses to repetitive nerve stimulation. The most reliable tests were the measure of miniature endplate potentials and determination of the number of AChRs per neuromuscular junction in the diaphragms of the recipient mice. Passive transfer of immunoglobulins from $94 \%$ of patients resulted in decreased mepp amplitudes, decreased AChRs at neuromuscular junctions, or both. ${ }^{29}$ Purification of immunoglobulin by column chromatography showed that the active fraction was IgG, while IgM was without effect. Furthermore, absorption of IgG by staphylococcal protein A completely eliminated the myasthenogenic effect of the immunoglobulin preparation. Thus, the passive transfer experiment clearly demonstrated the pathogenicity of IgG from myasthenic patients.

\section{Effect of myasthenic IgG on AChRs}

Theoretically, myasthenic patients' IgG might reduce the number of available AChRs by several possible 
mechanisms:

(1) It might alter the turnover of AChRs, either by increasing the rate of degradation or by decreasing the rate of synthesis.

(2) It might block the active site of the receptor.

(3) It might damage the AChRs, possibly in conjunction with complement or cellular elements or both.

The evidence now available suggests that accelerated degradation of AChRs, blockade, and damage may all be involved.

\section{Accelerated degradation of AChRs}

The studies of the effects of myasthenic IgG on receptor degradation were first carried out in a tissue culture system, using a modification of the method of Devreotes and Fambrough. ${ }^{30}$ The AChRs are first labelled with ${ }^{125} I-\alpha$-BuTx. As the AChR-125I- $\alpha$-BuTx complexes are endocytosed and degraded, the ${ }^{125} \mathrm{I}$ is released into the culture medium, primarily in the form of iodotyrosine. The rate of degradation of AChRs can be readily calculated from the rate of release of ${ }^{125} \mathrm{I}$ in the medium, and is normally approximately $4 \%$ per hour for rat skeletal muscle. When IgG from myasthenic patients was added to the cultures, the AChR degradation rate increased up to two-to three-fold, as compared with the cultures treated with control IgG. ${ }^{31}$ The antibody-induced acceleration is triggered by IgG alone without requiring other humoral or cellular components of the immune system. Both the normal receptor degradation process and the acceleration produced by myasthenic immunoglobulin are temperature-dependent, suggesting that they involve the active participation of the muscle cells. Suggesting that this must be a very common phenomenon, approximately $75 \%$ of myasthenic patients' serum immunoglobulins produced accelerated degradation of $\mathrm{AChRs},{ }^{32}$. Similar results have also been reported from other laboratories, using immunoglobulin preparations from human myasthetic patients ${ }^{33}$ or EAMG animals. ${ }^{34}$

Mechanism of accelerated AChR degradation ( fig I) (a) Cross linking. We wondered whether the accelerated degradation effect might be due to the ability of each IgG molecule to bind two molecules of AChR ${ }^{35}$ lgG molecules are known to be Y-shaped, with two arms capable of binding to two identical antigenic sites, and therefore cross-linking them. For this study, we prepared pure IgG, divalent $F\left(a b^{\prime}\right)_{2}$, and monovalent $\mathrm{Fab}$ fragments from myasthenic sera, by standard purification and enzymatic cleavage methods. When added to muscle cultures, the IgG (fig 1A) and divalent $F\left(a b^{\prime}\right)_{2}$ fragments (fig 1B) produced equivalent accelerated rates of

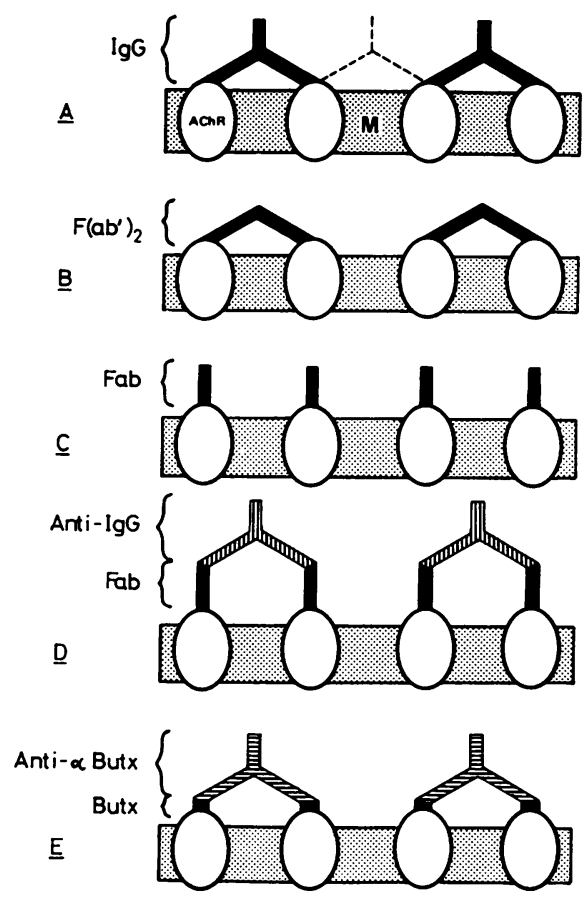

Fig 1 Diagrammatic representation of cross-linking of receptors by the various antibody fragments.

$M$ denotes muscle membrane, AChR acetylcholine receptor, and $\alpha-B u T x \alpha$-bungarotoxin. Acceleration of degradation was observed in the experimental conditions shown in panels $A, B, D$, and $E$, Fab alone failed to accelerate acetylcholine-receptor degradation.

(Reprinted by permission of New England Journal of Medicine 298:1120, 1978).

receptor degradation. By contrast, the monovalent Fab fragments failed to accelerate the degradation rate (fig 1C), although they bound to AChRs in cultured skeletal muscle. This suggested that crosslinking of AChRs might account for the effect of the IgG molecule or its divalent fragment. To test the cross-linking hypothesis further, we carried out additional experiments:

(1) Monovalent Fab antibody fragments were first added to the cultures. In this case, a second "piggyback" antibody, directed against the antibody fragments was then added (fig 1D). The effect of the second antibody was to cross-link the Fab fragments, thus indirectly cross-linking the AChRs. This manoeuver had the same effect in accelerating AChR degradation as did the original divalent antibodies.

(2) In this experiment, we wished to determine whether direct contact of an antibody with the AChR was necessary for accelerated degradation, or 
whether cross-linking per se could produce the same effect. To answer this question, we again used a "piggyback" technique, but here $\alpha$-BuTx rather than an antibody fragment was attached to the AChRs. Antibodies against $\alpha$-BuTx were prepared by immunising rabbits with $\alpha$-BuTx. When cultures labelled with ${ }^{125} \mathrm{I}-\alpha$-BuTx were treated with the antibodies, the degradation rate was again accelerated two-to three-fold (fig 1E). The specificity of this effect was demonstrated by control experiments in which the binding sites of the antibodies were blocked by adding $\alpha$-BuTx, which completely abolished its effect on degradation. This experiment clearly demonstrated that accelerated degradation is attributable to cross-linking via interposed $\alpha$-BuTx, without requiring direct contact between antibody and AChR.

(b) Selectivity of degradation. Theoretically, the myasthenic IgG might increase AChR degradation by: (a) accelerating the muscle cell's overall receptor degrading mechanism, or (b) altering only AChRs to which $\mathrm{IgG}$ is bound, so that the receptors are selectively degraded at a more rapid rate. Our results $^{36}$ favour the latter possibility.

We prepared cultures in which one set of AChRs was directly exposed to myasthenic patients' IgG for two hours; a second set of AChRs was allowed to develop immediately after the IgG exposure. Each set of receptors was separately labelled with ${ }^{125} \mathrm{I}-\alpha$-BuTx, and its degradation rate independently followed. ${ }^{36}$ (See fig 2 for details.) Our findings showed that only the set of AChRs directly exposed to myasthenic $\operatorname{Ig} G$ (and therefore having bound $\operatorname{IgG}$ ) was degraded at an accelerated rate two to three times normal, while the second set of receptors (without bound IgG) was degraded at the control rate. This suggested that the binding of IgG altered the receptors in some way that caused them to be preferentially selected for degradation.

(c) Mechanism of loss of AChRs. There is considerable evidence that the normal AChR degradation process begins by endocytosis or "internalisation" of AChRs, which are then degraded by lysosomal enzymes. Presumably, the mechanism of accelerated degradation also involves endocytosis and enzymatic lysis. In both normal and antibody-treated cultures, lowering the temperature to $10^{\circ} \mathrm{C}$ prevents degradation, indicating that it is an active, energydependent process. The role of lysosomal enzymes in this process is demonstrated by the marked effect of the lysosomal enzyme inhibitors, leupeptin and antipain, in muscle cultures. Both the normal and the antibody-accelerated degradation rates are greatly slowed by these agents (table 1).

There is increasing evidence that endocytosis rather than lysosomal degradation is the rate

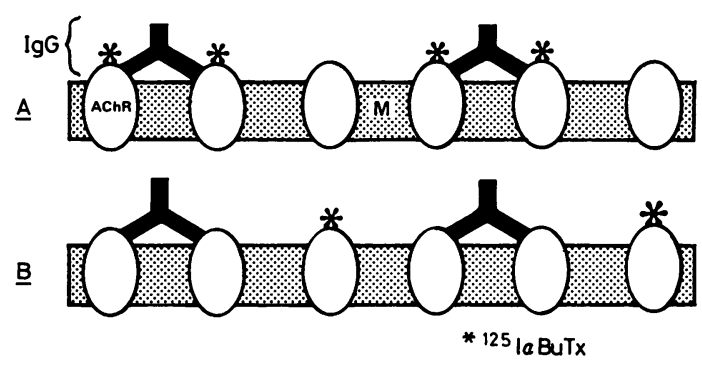

Fig 2 Cultures in set $A$ were first labelled with ${ }^{125} I-\alpha-B u T x$ then treated for two hours with myasthenic IgG. The labelled receptors have bound IgG. The cultures in set $B$ were first treated with myasthenic IgG. All existing AChRs were then blocked with unlabelled $\alpha-B u T x$. After six hours of incubation to allow for synthesis and incorporation of additional AChRs, the new AChRs were labelled with ${ }^{125} I-\alpha-B u T x$. Thus, the labelled AChRs do not have bound IgG, although other receptors in the same cultures $d o$.

The degradation rate of labelled AChRs in set A (with bound $\operatorname{IgG)}$ was accelerated while that of labelled AChRs in set B (without bound IgG)was not accelerated.

limiting step in the process of removal of AChRs: (1) As indicated above, ${ }^{36}$ two different rates of degradation can occur simultaneously in a single muscle culture, antibody-bound AChRs being

Table 1 Effects of protease innibitors on degradation rates of $A C h$ receptors

\begin{tabular}{lcc}
\hline & Control IG & Myasthenic IG \\
\hline No inhibitor & $5 \cdot 1 \% \pm 0.35$ & $10.9 \% \pm 1 \cdot 12$ \\
Leupeptin $100 \mathrm{ug} / \mathrm{ml}$ & $2 \cdot 5 \% \pm 0.17$ & $6 \cdot 1 \% \pm 0.65$ \\
Antipain $100 \mathrm{ug} / \mathrm{ml}$ & $2 \cdot 8 \% \pm 0.00$ & $6.6 \% \pm 0.17$ \\
\hline
\end{tabular}

Effects of protease inhibitors on degradation rates of AChRs. Sets of 15 cultures were treated with control immunoglobulin or a myasthenic patient's immunoglobulin as indicated. Inhibitors of lysosomal enzymes were added to sets of 5 cultures each. Mean degradation rates are given as percent of AChRs degraded per hour \pm S.D. Note that both leupeptin and antipain inhibit degradation in control cultures and in cultures treated with myasthenic immunoglobulin.

degraded more rapidly than those without bound antibody. This fits the concept of a selective increase in endocytosis brought about by the antibody, but is not consistent with an overall increase in the lysosomal degradation rate. (2) Further, Goldberg et al have reported that treatment of chick muscle cultures with lysosomal enzyme inhibitors retards the release of degradation products into the medium, but does not slow the rate of loss of AChRs from the surface membrane. ${ }^{37}$ the above findings support the concept that the endocytotic step is rate limiting for both normal and antibody-treated AChRs, while the lysosomal enzyme system is capable of degrading all the AChRs 
presented to it, unless it is specifically inhibited.

Since many patients benefit from treatment with adrenal corticosteroids, we wondered whether these hormones might in some way reduce the effect of antibody on AChRs. The addition of hydrocortisone, up to $0.5 \mathrm{mg} / \mathrm{ml}$ to IgG-treated muscle cultures, failed to interfere with the accelerated degradation produced by myasthenic patients' antibody (table 2 ). (d) How does myasthenic antibody enhance endocytosis? Although it is clear that myasthenic antibody must cross-link AChRs to induce accelerated degradation, it is not yet certain how cross-linking increases the rate of endocytosis. Autoradiography ${ }^{38}$ and fluorescence microscopy ${ }^{39}$ suggest that the addition of antibody from myasthenic patients or EAMG animals causes receptor aggregation. The most likely possibility is that the cross-linked AChR aggregates are recognised because of altered size or mobility within the membrane, and preferentially selected for accelerated degradation.

Effect of myasthenic immunoglobulin on AChRs at intact neuromuscular junctions.

There are important differences between the extrajunctional AChRs of cultured muscle, and AChRs of neuromuscular junctions, with respect to physical properties, pharmacology, and kinetics of turnover. 40 These differences have raised questions about the applicability of results of tissue culture experiments to the situation at intact neuromuscular junctions. We therefore studied the effects of myasthenic immunoglobulin on the turnover of AChRs at intact mammalian neuromuscular junctions, both in vivo and in vitro. ${ }^{41}$ Labelling of AChRs of intact mouse diaphargms was accomplished by intrathoracic injection of ${ }^{125} \mathrm{I}-\alpha-\mathrm{BuTx}$, and restriction of the mice in the vertical position to allow the toxin to gravitate to the diaphragms. The mice were then given daily intraperitoneal injections of immunoglobulin from individual myasthenic patients or from a control pool. At intervals of 0 to four days, the mice were killed, and the ${ }^{125} \mathrm{I}-\alpha$-BuTx bound to the diaphragms was determined by gamma counting. The mice treated with myasthenic immunoglobulin showed a loss of radioactivity two to three times as rapid as in the diaphragms of control mice. This indicated a more rapid loss of AChRs (fig 3). Similar results have been obtained using sera from EAMG rats and whole diaphragms in vitro. ${ }^{53} 54$

In order to determine whether the loss of AChRs was due to degradation, diaphragms from mice treated in the same way were maintained in organ culture for more than 24 hours. Again, the diaphragms treated with myasthenic patients' IG showed a three-fold acceleration of loss of radio-
Table 2 Effect of hydrocortisone on degradation rates of $A C h$ receptors

\begin{tabular}{|c|c|c|c|c|}
\hline \multicolumn{5}{|c|}{ Concentration of hydrocortisone $\mathrm{mg} / \mathrm{ml}$} \\
\hline & 0.5 & $0 \cdot 1$ & 0.01 & 0 \\
\hline \multicolumn{5}{|c|}{ Control } \\
\hline IG & $3 \cdot 76 \% \pm 0 \cdot 15$ & $3 \cdot 25 \% \pm 0 \cdot 13$ & $3 \cdot 75 \% \pm 0 \cdot 11$ & $4.01 \% \pm 0.1$ \\
\hline MG 1 & $11.59 \% \pm 0.99$ & $10.62 \% \pm 0.21$ & $10.87 \% \pm 0.77$ & $10.87 \% \pm 0.93$ \\
\hline MG 2 & $9.09 \% \pm 0.31$ & $8 \cdot 83 \% \pm 1 \cdot 11$ & $8.71 \% \pm 0.34$ & $9.04 \% \pm 0.34$ \\
\hline MG 3 & $9 \cdot 33 \% \pm 0.32$ & $9 \cdot 97 \% \pm 1 \cdot 00$ & $8 \cdot 72 \% \pm 0.25$ & $9.92 \% \pm 0.39$ \\
\hline
\end{tabular}

Effect of hydrocortisone on degradation rates of AChRs. Degradation rates of AChRs were determined as indicated in the text. Sets of 20 cultures were treated with immunoglobulin from three different myasthenic patients and a control pool. Hydrocortisone, in the concentration indicated, was added to sets of five cultures treated with each serum immunoglobulin preparation. Mean degradation rates are given as percent of $\mathrm{AChRs}$ degraded per hour \pm S.D. Note the lack of effect of hydrocortisone on either the normal or accelerated degradation rates.

activity. The radioactive material released into the culture medium was collected and analyzed by column chromatography. It consisted of a low molecular weight substance, which co-migrated with monoiodotyrosine (fig 4). Our findings thus con-

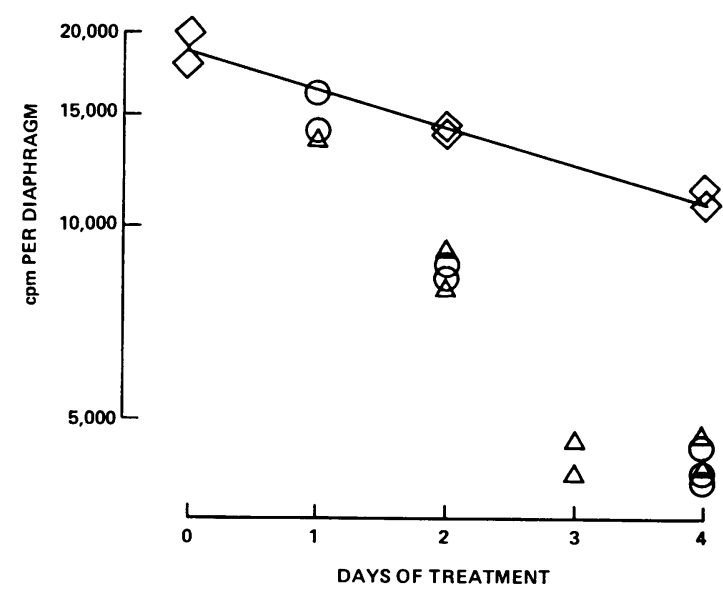

Fig 3 Effect of in vivo treatment with myasthenic or control IG on the ACh receptors of mouse diaphragms. Diaphragms were labelled by an intrathoracic injection of ${ }^{125} I-\alpha-B u T x$. The mice were given daily doses of $I G$ from pooled serums of control patients $(\diamond)$ or from two different myasthenic patients $(\bigcirc, \triangle)$. The diaphragms were removed at intervals after the beginning of treatment (time zero), and the radioactivity remaining was counted. Each point represents the number of counts per minute recorded from a whole diaphragm of a mouse killed at the time indicated after the first IG treatment. The rate of loss of radioactivity in the diaphragms of mice treated with myasthenic IG is increased, as compared to that of the controls.

(Reprinted by permission of Science, 200:1285, 1978). 


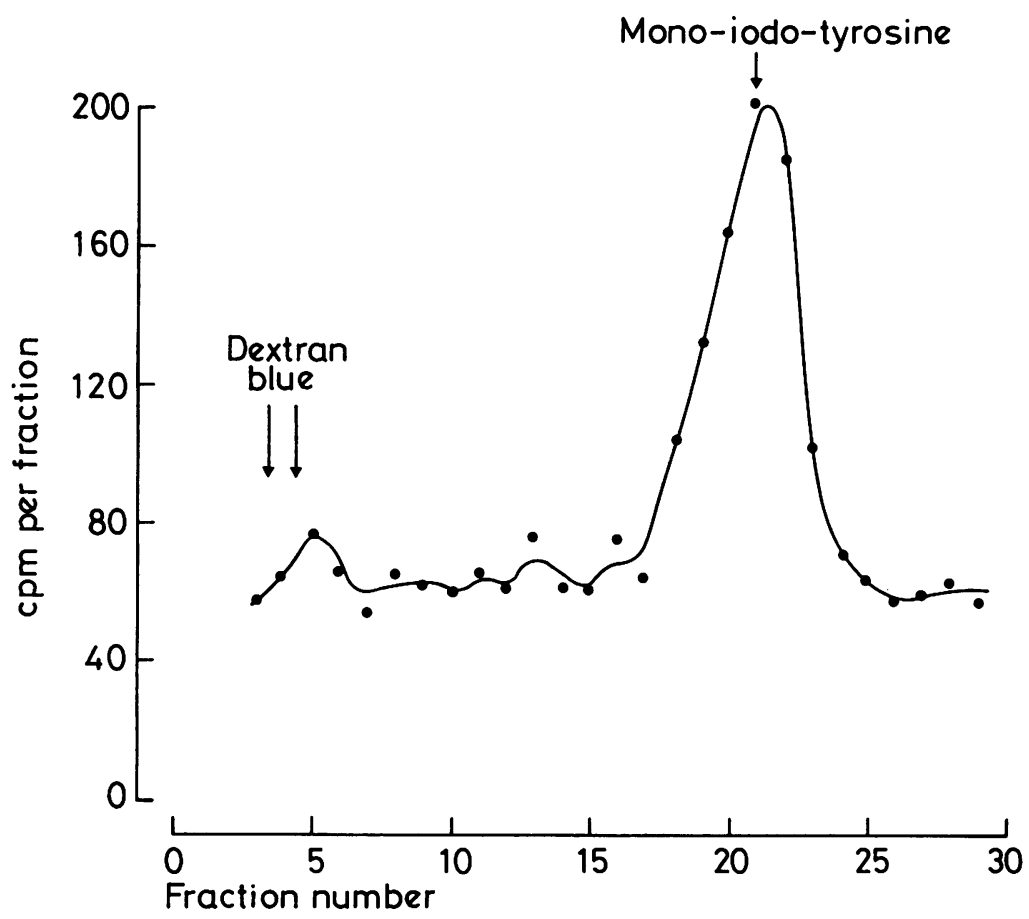

Fig 4 Chromatogram of culture medium collected from $a$ diaphragm following an 8-hour culture period. The diaphragm was labelled in vivo with ${ }^{125} I-\alpha-B u T x$ and treated with IG from a myasthenic patient. Each point represents the radioactivity recorded in a $1.25 \mathrm{ml}$ fraction eluted with tris buffer $(0.05 \mathrm{M}$, pH 7.4) from a Sephadex G-15 column $(1$ by $13 \mathrm{~cm})$. More than $90 \%$ of the radioactivity was eluted at the same position as carrier monoiodot yrosine (unlabelled). Less than 5.0\% appeared in the void volume, marked by the high-molecularweight dye dextran blue. (Reprinted by permission of Science, 200:1286, 1978).

firmed the degradative nature of the process. These observations indicated that immunoglobulin from myasthenic patients increases the rate of degradation of AChRs at intact neuromuscular junctions of mammalian muscles. This process may represent an important antibody mediated mechanism in human MG.

Blockade of the active site of the AChR

The analogy between MG and curare-like blockade of neuromuscular transmission was first pointed out to Mary Walker by D. Denny-Brown, providing the background for her trial of physostigmine. Moreover, Simpson's 1960 hypothesis $^{7}$ suggested a curare-like antibody capable of blocking AChRs. The first demonstration of anti-AChR antibody in the serum of myasthenic patients was based on its ability to block $\alpha$-BuTx binding, ${ }^{20}$ but only a minority (5 of 15) of myasthenic patients' sera produced significant blockade in that report, using solubilised $\mathrm{AChR}$ as the test antigen. In reviewing the literature, it appears that the role of AChR site blockade in the pathogenesis of MG has been a matter of continuing controversy. ${ }^{42-44}$

We have recently developed a method to measure blockade of the active site of AChRs by myasthenic immunoglobulin, using the rat skeletal muscle culture system. The cultures are cooled to $4^{\circ} \mathrm{C}$ to eliminate degradation, and to minimise possible dissociation of antibody. They are treated overnight in the cold with immunoglobulin prepared from myasthenic patients' sera, and are then saturated with ${ }^{125} \mathrm{I}-\alpha$-BuTx. The loss of $\alpha$-BuTx binding sites in the cultures treated with myasthenic immunoglobulin is attributable to AChR blockade. Our findings indicate that serum immunoglobulin from approximately $80 \%$ of myasthenic patients produced significant blockade of ${ }^{125} \mathrm{I}-\alpha$-BuTx binding. It is not certain whether this represents binding of the antibody directly at, or near, the active site of the AChR. In the latter instance, steric hindrance could account for the blocking effect. Finally, it remains to be seen to what extent AChR bloackade contributes to the clinical manifestations of MG in individual patients.

Complement mediated mechanism of AChR loss The effect of complement on AChRs was first demonstrated in the mouse passive transfer model. ${ }^{29}$ To test the effect of complement, we depleted mice of the $\mathrm{C} 3$ component by the use of "cobra venom factor," a purified fraction derived from the venom of the Indian cobra Naja naja. ${ }^{45}$ The C3- depleted mice, and non-depleted controls were treated with 
immunoglobulins from seven different patients. In each case, the C3-depleted mice showed a reduced effect of the immunoglobulin on mepp amplitudes and numbers of AChR per neuromuscular junctions. To test the effect of the latter part of the complement system, we used pairs of C5-deficient and nondeficient strains of mice. Injection of myasthenic immunoglobulin produced equivalent changes in mepp amplitudes and AChRs in both strains of mice. The participation of the early part of the complement systems up to and including $\mathrm{C} 3$ in this reaction implies that some effector system in addition to the binding of antibody to receptor may be involved in the pathogenesis of myasthenia. However, the lack of participation of the latter part of the complement cascade (C5-C9) in the cases tested suggests that cell lysis is not required in this reaction, since activation of $\mathrm{C} 5$ through $\mathrm{C} 9$ generally leads to cytolytic effects.

These findings have received further support from morphological studies demonstrating $\mathrm{C} 3$ at neuromuscular junctions of myasthenic patients ${ }^{46}$ and by studies of complement fixation by antibody from myasthenic patients. ${ }^{47}$

We wondered whether complement might play a role in the mechanisms of accelerated degradation and blockade described above. To test this, we again used the rat skeletal muscle tissue culture system. Immunoglobulin from each of four different patients and a control pool was added to rat skeletal muscle cultures. In each case, fresh human complement, heat-inactivated complement or no complement was added to the dishes. At the end of three hours, the cultures were saturated with ${ }^{125} \mathrm{I}-\alpha-\mathrm{BuTx}$,

Table 3 Effect of complement on IG-induced loss of ACh receptors

\begin{tabular}{lll}
\hline IG & Complement & $\begin{array}{l}\text { Bound } 125 I-\alpha-B u T x \\
\text { cpm }+ \text { S.D. }\end{array}$ \\
\hline Control & + & $35512 \pm 1483$ \\
Control & $\Delta$ & $35324 \pm 1421$ \\
MG 1 & + & $28157 \pm 623$ \\
MG 1 & $\Delta$ & $30239 \pm 2238$ \\
MG 2 & + & $26379 \pm 1957$ \\
MG 2 & $\Delta$ & $27816 \pm 2195$ \\
MG 3 & + & $24055 \pm 1684$ \\
MG 3 & $\Delta$ & $25048 \pm 2763$ \\
MG 4 & + & $18191 \pm 1461$ \\
MG 4 & $\Delta$ & $20527 \pm 558$
\end{tabular}

Sets of five cultures each were treated with immunoglobulin from each of four different myasthenic patients or control pool, and with fresh or heat-inactivated human complement $(0.3 \mathrm{ml}$ whole serum). At the end of three hours of incubation at $37^{\circ} \mathrm{C}$, the cultures were saturated with $125 I-\alpha-B u T x$, extracted with Triton $X-100$ and counted. Note the loss of $\alpha-B u T x$ binding sites in all cultures treated with myasthenic patients' serum, and the absence of additional effect of complement. Each of the myasthenic immunoglobulins used had previously been tested in vivo in the mouse passive transfer model, and its effect had teen enhanced in vivo by complement. These results suggest that the effect of complement is not related to accelerated degradation or blockade of $\mathrm{AChR}$. washed, and extracted with Triton $\mathrm{X}-100$. In all cases, the experiments showed that the loss of AChRs induced by myasthenic immunoglobulin was not enhanced by the addition of active complement (table 3). It thus appears unlikely that complement plays a role in accelerated degradation or blockade induced by myasthenic antibody. What effect does complement have on AChRs? Electron micrographs of neuromuscular junctions from myasthenic patients show that the postsynaptic membrane sometimes undergoes destructive changes. Fragments of membrane with bound complement appear to be released into the synaptic cleft, or occasionally undergo phagocytosis by macrophages. 4648 Ultimately, the synaptic folds become shortened and simplified. It is not yet clear to what extent the simplification results from complementinduced damage. Alternatively, postsynaptic membrane could be lost as a result of endocytosis during the process of accelerated degradation of AChRs.

\section{Functional alteration of AChRs}

The mechanisms described above all contribute to the loss or blockade of AChRs. However, the possibility that antibody might also interfere functionally with the AChR-ion translocation mechanism has also been considered. Studies of acetylcholine "noise" have revealed that the open time of ionic channels was normal at neuromuscular junctions of myasthenic patients. ${ }^{49}$ Other possible mechanism, such as an antibody-induced change in the AChR's affinity for ACh have yet to be explored.

\section{Cell mediated immunity}

The present discussion has focused on humoral factors effecting a loss of available AChRs in myasthenia gravis. However, the possibility that cell-mediated immune responses are also involved has been suggested. It is known that lymphocytes from myasthenic patients are stimulated by the presence of purified AChR to undergo blast transformation when incubated in the presence of AChR from electric eels. ${ }^{50} 51$ In general, stimulation of lymphocytes in response to a specific antigen indicates that the cells have previously been sensitised to that antigen. It is not yet known, however, whether the responding lymphocytes in MG are $T$ cells or B cells, or whether they are capable of participating in cell-mediated effector responses. Histological studies of skeletal muscles from myasthenic patients have revealed occasional local collections of lymphocytes ("lymphorrhages"), suggestive of a cell-mediated process. ${ }^{52}$ However, the rarity of these findings at neuromuscular junctions suggests that direct cell-mediated destruction of 
AChRs may not be important in most cases of MG.

In 1934 Mary Walker wrote her famous letter to the Lancet describing the remarkable effect of physostigmine in a patient with myasthenia gravis (MG). ${ }^{1}$ This provided the first evidence directly implicating an abnormality of the neuromuscular junction in MG. In the debate that followed, it was variously suggested that the motor neuron, ${ }^{2}$ nerve terminal, ${ }^{34}$ neurotransmitter, ${ }^{5}$ receptor, ${ }^{6}$ or postsynaptic membrane $^{4}{ }^{6}$ was the locus of the defect. With remarkable perspicacity, Professor Simpson, to whose honor this paper is dedicated, forthrightly suggested that the acetylcholine "receptor"-at that time merely a hypothetical construct-was primarily involved, and postulated that it was blocked by an autoantibody. ${ }^{7}$ With the methods then available, the hypothesis could not be tested. It was not until 1973 that we were able to identify the precise nature of the defect in MG as a decrease of available acetylcholine receptors (AChR) at neuromuscular junctions. ${ }^{8}$ In large measure, this was made possible by the availability of neurotoxins that bind specifically to AChRs, including $\alpha$-Bungarotoxin ( $\alpha$-BuTx) and other elapid toxins. ${ }^{9}$ During the past seven years, our understanding of the pathogenesis of the receptor defect in $\mathrm{MG}$, and a rational basis for treatment, have progressed with remarkable rapidity. ${ }^{10}$ The purpose of this paper is to summarise studies that have contributed to the current concepts of the mechanism of AChR loss in MG.

We are deeply indebted to the many colleagues who participated in the studies described here, including D Fambrough, S Satya-Murti, F Slone, K. Toyka, I Kao, D Griffin, J Winkelstein, C Angus, K Fischbeck, A Murphy, J Michelson, and G Hoffman. Ms C Barlow provided expert assistance with the manuscript. The original research carried out in the authors' laboratory was supported in part by NIH grants No 5PO1NS10920 and No 5RO1HD04817 and grants from the Musuclar Dystrophy Association and the Myasthenia Gravis Foundation.

\section{References}

1 Walker MB. Treatment of myasthenia gravis with physostigmine. Lancet 1934; 1:1200-1.

2 Engel WK, Warmolts JR. Myasthenia gravis: A new hypothesis of the pathogenesis and a new form of treatment. Ann NY Acad Sci 1971; 183:72-87.

3 Elmqvist D, Hofmann WW, Kugelberg J, Quastel DMJ. An electrophysiological investigation of neuromuscular transmission in myasthenia gravis. J Physiol 1964; 174:417-34.

4 Engel AG, Santa T. Histometric analysis of the ultrastructure of the neuromuscular junction in myasthenia gravis and in the myasthenic syndrome. Ann NY Acad Sci 1971; 183-46-63.

5 Grob D, Johns RJ, Harvey AM. Studies in neuromuscular function IV. Stimulating and depressing effect of acetylcholine and choline on patients with myasthenia gravis, and their relationships to the defect in neuromuscular transmission. Bull Johns Hopkins Hosp 1956; 99:153-81.

6 Bergman R, Johns RJ. Ultrastructural alterations in muscle from patients with myasthenia gravis and Eaton-Lambert syndrome. Ann NY Acad Sci 1971; 183:88-122.

7 Simpson JA. Myasthenia gravis: A new hypothesis. Scottish Med J 1960; 4:419-36.

8 Fambrough DM, Drachman DB, Satyamurti S. Neuromuscular junction in myasthenia gravis: Decreased acetylcholine receptors. Science 1973; 182:293-5.

9 Lee CY. Chemistry and pharmacology of polypeptide toxins in snake venoms. Ann Rev Pharmacol 1972; 12:265-86.

10 Drachman DB. Myasthenia gravis: 2 Parts. $N$ Engl J Med 1978; 136-142, 186-193.

11 Drachman DB, Fambrough DM, Satyamurti S. Reduced acetylcholine receptors in myasthenia gravis. Trans Am Neurol Asso 1973; 98:21-3.

12 Drachman DB, Kao I, Pestronk A, Toyka KV. Myasthenia gravis as a receptor disorder. Ann $N Y$ Acad Sci 1976; 274:226-34.

13 Ito $\mathbf{Y}$, Miledi R, Vincent A, Newsom-Davis J. Acetylcholine receptors and electrophysiological function in myasthenia gravis. Brain 1978; 345-68.

14 Albuquerque EX, Rash JE, Mayer RF, Satterfield JR. An electrophysiological and morphological study of the neuromuscular junctions in patients with myasthenia gravis. Exper Neurol 1976; $51: 536-63$

15 Chang CC, Lee CY. Electrophysiological study of neuromuscular blocking action of cobra neurotoxin. Br J Pharmac Chemother 1966; 28:172-81.

16 Satyamurti S, Drachman DB, Slone F. Blockade of acetylcholine receptors: A model of myasthenia gravis. Sciecne 1975; 187:955-7.

17 Desmedt JE. The neuromuscular disorder in myasthenia gravis. In: JE Desmedt ed, New Developments in EMG and Clinical Neurophysiology. Basle: S. Karger 1973: 241-304.

18 Nastuk WL, Plescia OJ, Osserman KE. Changes in serum complement activity in patients with myasthenia gravis. Proc Soc Exp Biol 1960; 105: 177-84.

19 Patrick J, Lindstrom J. Autoimmune response to acetylcholine receptor. Science 1973; 180:871-2.

20 Almon RR, Andrew CG, Appel SH. Serum globulin in myasthenia gravis: Inhibition of $\alpha$-bungarotoxin binding to acetylcholine receptors. Science 1974; 186:55-7.

21 Bender AN, Engel WK, Ringel SP, Daniels MP, Vogel Z. Myasthenia gravis: A serum factor blocking acetylcholine receptors of the human neuromuscular junction. Lancet $1975 ; 1: 607-8$.

22 Appel SH, Almon RR, Levy N. Acetylcholine 
receptor antibodies in myasthenia gravis. $N$ Engl J Med 1975; 293:760-1.

23 Lindstrom JM, Seybold ME, Lennon VA, Whitttingham S, Duane DD. Antibody to acetylcholine receptor in myasthenia gravis: Prevalence, clinical correlates, and diagnostic value. Neurology 1976; 26:1054-9.

24 Mittag T, Kornfeld P, Tormay A, Woo C. Detection of antiacetylcholine receptor factors in serum and thymus from patients with myasthenia gravis. $N$ Engl J Med 1976; 294:691-4.

25 Namba T, Brown SB, Grob D. Neonatal myasthenia gravis: Report of two cases and review of the literature. Pediatrics 1970; 45:488-504.

26 Bergh NP. Biologic assays in myasthenia gravis for any agents causing a neuromuscular block. Scand $J$ Clin Invest 1953; 5:Supp 5 5-47.

27 Nastuk WL, Strauss AJL. Further developments in the search for a neuromuscular blocking agent in the blood of patients with myasthenia gravis. In: H.R. Viets, ed. Myasthenia Gravis. Springfield: CC Thomas, 1961: 229-37.

28 Toyka KV, Drachman DB, Pestronk A, Kao I. Myasthenia gravis: Passive transfer from man to mouse. Science 1975; 190:397-9.

29 Toyka KV, Drachman DB, Griffin DE, Pestronk A, Winkelstein JA, Fischbeck KH, Kao I. Myasthenia gravis: Study of humoral immune mechanisms by passive transfer to mice. $N$ Engl $J$ Med 1977; 296:125-31.

30 Devreotes PN, Fambrough DM. Acetylcholine receptor turnover in membranes of developing muscle fibers. J Cell Biol 1975; 65:335-58.

31 Kao I, Drachman DB. Myasthenic immunoglobulin accelerates $\mathrm{ACh}$ receptor degradation. Science 1977; 196:527-9.

32 Drachman DB, Adams RN, Josifek LF, in preparation.

33 Appel SH, Anwyl R, McAdams MW, Elias S. Accelerated degradation of acetylcholine receptor from cultured rat myotubes with myasthenia gravis sera and globulins. Proc Nat Acad Sci 1977; 74:2130-4.

34 Heinemann S, Bevan S, Kullberg R, Rice J. Modulation of acetylcholine receptor by antibody against the receptor. Proc Nat Acad Sci 1977; 74:3090-4.

35 Drachman DB, Angus CW, Adams RN, Michelson J, Hoffman GJ. Myasthenic antibodies cross-link acetylcholine receptors to accelerate degradation. $N$ Eng J Med 1978; 298:1116-22.

36 Drachman DB, Angus CW, Adams RN, Kao I. Effect of myasthenic patients' immunoglobulin on acetylcholine receptor turnover: Selectivity of degradation process. Proc Nat Acad Sci 1978: 75:3422-6.

37 Goldberg AL, DeMartino GN, Libby P. Influence of Thyroid Hormones and Protease-Inhibitors on Protein Degradation in Skeletal Muscle. In: Aguayo AJ, Karpati G, eds Current Topics in Nerve \& Muscle Research. Amsterdam: Excerpta Medica 1979; 53-60.
38 Tarrab-Hazdai R, Yaffe D, Prives Y, Amsterdam A, Fuchs S. Effects of Macrophages and Antibodies from Myasthenic Animals on Muscle Cells in Culture. In: Dau P, ed. Plasmapheresis and the Immunobiology of Myasthenia Gravis, 19:32-40. Boston: Houghton Mifflin, 1979.

39 Lennon VA. Immunofluorescence Analysis of Surface Acetylcholine Receptors of Muscle: Modulation by Auto-Antibodies. In: Jender DJ ed. Cholinergic Mechanisms and Psychopharmacology New York: Plenum Press, 1978: 77-92.

40 Brockes JP, Berg DK, Hall ZW. The biochemical properties and regulation of acetylcholine receptors in normal and denervated muscle. Cold Spring Harbor Symposium Quant. Biol 1975; 40:253-62.

41 Stanley EF, Drachman DB. Effect of myasthenic immunoglobulin on acetylcholine receptor of intact mammalian neuromuscular junctions. Science 1978; 200:1285-7.

42 Albuquerque EX, Lebeda JF, Appel SH, et al. Effects of normal and myasthenic serum factors on innervated and chronically denervated mammalian muscles. Ann NY Acad Sci 1976; 274:475-92.

43 Lindstrom J. Immunological studies of acetylcholine receptors. J Supramolecular Structure 1976; 4: 389-403.

44 Penn AS. Immunological Features of Myasthenia Gravis. In: Aguayo AJ and Karpati G, eds. Topics in Nerve \& Muscle Research. Amsterdam: Excerpta Medica, 1975: 123-32.

45 Winkelstein JA, Smith MR, Shin HS. The role of C3 as an opsonin in the early stages of infection Proc Soc Exp Med 1975; 149:397-401.

46 Engel AG, Lambert EH, Howard FM. Immune complexes (IgG and C3) at the motor end-plate in myasthenia gravis. Mayo Clinic Proc 1977; 52: 267-80.

47 Tarrab-Hazdi R, Abramsky O, Fuchs S. Humoral antibodies to acetylcholine receptor in patients with myasthenia gravis. Lancet 1975; II:340-2.

48 Rash JE, Albuquerque EX, Hudson CS, Mayer RF, Satterfield JR. Studies on human myasthenia gravis. Electrophysiological and ultrastructural evidence compatible with antibody labelling of the acetylcholine receptor complex. Proc Natl Acad Sci 1976; 73:4584-8.

49 Cull-Candy SG, Miledi R, Trautman A. End-plate currents and acetylcholine noise at normal and myasthenic human end-plates. J Physiol 1979; 287:247-65.

50 Abramsky O, Aharonov A, Webb C, Fuchs S. Cellular immune response to acetylcholine receptorrich fraction, in patients with myasthenia gravis. Clin Exp Immunol 1975; 19:11-16.

51 Richman DP, Patrick J, Arnason BGW. Cellular immunity in myasthenia gravis. N Eng J Med 1976; 294:694-8.

52 Russell DS. Histologic changes in the striped muscles in myasthenia gravis. $J$ Path Bact 1953; 65:279-89.

53 Heinemann S, Merlie J, Lindstrom J. Modulation 
of acetylcholine receptor in rat diaphragm by anti-receptor sera. Nature 1979; 274:65-8.

54 Reiness CW, Weinberg CB, Hall ZW. Antibody to acetylcholine receptor increases degradation of junctional and extrajunctional receptors in adult muscle. Nature 1978; 274:68-70. 